\title{
Effect of Low Intensity Dance Exercise: Hostility, Anxiety and Depression among Sedentary Overweight Women in Malaysia
}

\author{
Mastura Johar ${ }^{*}$, Mardian Shah, Haizan Taha \\ Department of Social Science, Universiti Tenaga Nasional, Malaysia
}

Copyright $(2015$ Horizon Research Publishing All rights reserved.

\begin{abstract}
The purpose of this investigation is to evaluate the effect of a 12-week low intensity dance exercise intervention in the treatment of hostility subscale, anxiety subscale and depression subscale among overweight women working in Malaysia in an attempt of Sports for all. Forty subjects were recruited from both government and private sectors in Malaysia. Subjects were between the ages of 40 and 55 years, who have had a diagnosis of total stress score above the mean, were not enrolled in any exercise program or were physically inactive over the period of one year (sedentary) overweight (Body Mass Index above 25) and have had a cardiovascular endurance score below the mean. Subjects were randomly assigned to a 12-week low intensity dance exercise of "Aero mass", an intervention or a conventional aerobics dance exercise as the control group. A pretest-posttest control research design was utilized. Both groups met for 50 minutes, three times a week (36 sessions). The Transactional Approach Multidimensional (Derogatis Stress Profile) examined the hostility, anxiety and depression response sub-scale. Statistical analysis included (group $\mathrm{x}$ time) repeated measures ANOVA to determine between and within group mean differences. The hypotheses of the study received significant support. There were statistically significant differences between*group effect (between treatment and control groups) on the combined dependent variables: $F(4,35)=20.79, p<.01$, eta square $=.790$. An inspection of the mean scores indicated that treatment group reported an improvement for Hostility sub-scale $(\mathrm{M}=47.70$, $\mathrm{SD}=3.34)$, Anxiety sub-scale $(\mathrm{M}=35.65, \mathrm{SD}=3.64)$ and for Depression sub-scale $(\mathrm{M}=35.65, \mathrm{SD}=2.58)$. It is concluded that low intensity dance therapy exercise intervention of "Aero mass" had contributed greatly to the positive findings concerning physical health and psychological well-being among overweight women in Malaysia.
\end{abstract}

Keywords Dance Therapy, Low Intensity, Stress, Anxiety, Depression and Hostility

\section{Introduction}

The connection between physical and psychological well-being has been pursued for more than 2,000 years [20]. Wellness is a holistic concept and includes mental and physical components [29]. Hermon and Hazier [14] identified well-being as the attention to both mental and physical health. However, to date, the role of physical exercise has expanded to one of great importance in the promotion of physiological and psychological well-being [7][16][17][34]. The physical fitness "boom" which began in the 1970s resulted in considerable increase in focus on the importance of engaging in physical activity, this trend appears to continue as we move forward through 2012. Along with the belief that participation at five times a week, performing vigorous exercises of more than 150 minutes at moderate intensity per week will improve both the physical and psychological well-being [4]. Further to this, dance has been used as a healing ritual for thousands of years and has its historical roots among indigenous people [30]. Thus, dance itself has been ascribed to have a curative power whereby dance (movement) therapy has been developed in the last decades and follows a specific approach of treatment. Dance movement therapy's impact on stress management and stress reduction has not been addressed specifically by research. Dance movement therapy (DMT) is defined as a form of creative body oriented psychotherapy that uses movement, dance, and verbal intervention to further the emotional, cognitive, physical and social integration of the individual [1]. Music has been shown to be an effective intervention to achieve a range of desirable psychological and performance effects among athletes. Effects that have been demonstrated empirically include enhanced mood [15][33], arousal control [32], promotion of flow states [25], reduced perceived exertion [32] extended work output, improved skill acquisition [25], and enhanced performance [15]. However, evaluations of the potential benefits of dance as therapy for patients with certain illnesses such as obesity, breast cancer, brain damage, eating disorders, and alcoholism were often performed with suboptimal study designs [6][35]. Up until today, there is no comprehensive systematic review of randomized research concern. In 
Malaysia, The Health Ministry will be training more psychologists to reduce the rising number of suicide cases, generally caused by mental depression and encouraging the community to play a greater role in identifying people suffering from stress, mental depression and providing help (Stars, 2011). Health Minister Datuk Seri Liow Tiong Lai said that "there is a lack of psychologists in the country who are able to identify and treat those suffering from depression and stress as early detection is important to prevent the patients' condition from getting worse. The ministry's statistics in 2007 and 2008 stated that Chinese made up $53.5 \%$ of all suicide cases while $27.3 \%$ of them were Malays. Indian made up $13.9 \%$. The Star reported that two people commit suicide daily in Malaysia. Some experts believe the figure could be higher. Studies still needed to be carried out to look at the correlation of race and suicide cases. However, social stigma on depression was still very bad, and the lack of support from the community has prevented such patients from seeking medical help. This present study will help identify a non-clinical treatment for those facing psychological problems such as stress and depression and create awareness on mental health at schools, colleges, and organizations. Until recently, claims for the psychological benefits of physical exercise have tended to precede supportive evidence. Nevertheless, the pattern of evidence suggests the theory that exercise training recruits a process, which confers enduring resilience to stress. A study is conducted to observe any beneficial effect of dance exercise on hostility, anxiety and depression responses sedentary overweight women suffering from high stress level and low self-esteem [21]. This study allows the effects of exercise to be clearly understood in terms of existing psychobiological knowledge, and it can thereby provide the theoretical base that is needed to guide future research in this area. Further to that, individual can realize his or her own abilities, can cope with the normal stress, can work productively and fruitfully, and is able to contribute to his or her family. Therefore, to achieve some insight regarding the influence and effect of low intensity aerobics group dance exercise on the physiological well-being namely hostility, anxiety and depression responses subscales among working women, the following objectives are formulated. Firstly to identify the difference between the experimental (low impact dance exercise improvised local Malaysian music ) and control group (conventional aerobic dance) in terms of the difference between pre-test, post-test one and post-test two scores on psychological well-being in terms of hostility, anxiety and depression responses subscales. Secondly, to make recommendation based on the present study on the effectiveness of group dance therapy activity towards improving the future of preventative medicine and better the psychological health and lifestyle of sedentary overweight women to perform and increase productivity in their daily life.

\section{Methodology}

The research design used in this study is a quasi-experimental design, pre-test-post-test one and post-test two control group designs. Quasi-experiment design provides as much control as possible [10] [28]. A pre-test was administered to all participants of study to measure the level of psychological well-being variables (hostility, anxiety and depression responses subscales). The Derogatis Stress Profile (DSP) is a 77-item multidimensional self-report inventory was utilized [12][13] before treatment condition was introduced. Subjects were measured again at week eight and week 12 after the treatment is given [5]. The intervention condition for this research is low intensity dance exercise program conducted by the researcher. Subjects are required to participate in 36 sessions, 50 minutes each, 3 times per week for 12 weeks period. Figure 1 shows treatment assignment and the pre-test-post-test design used in this research study.

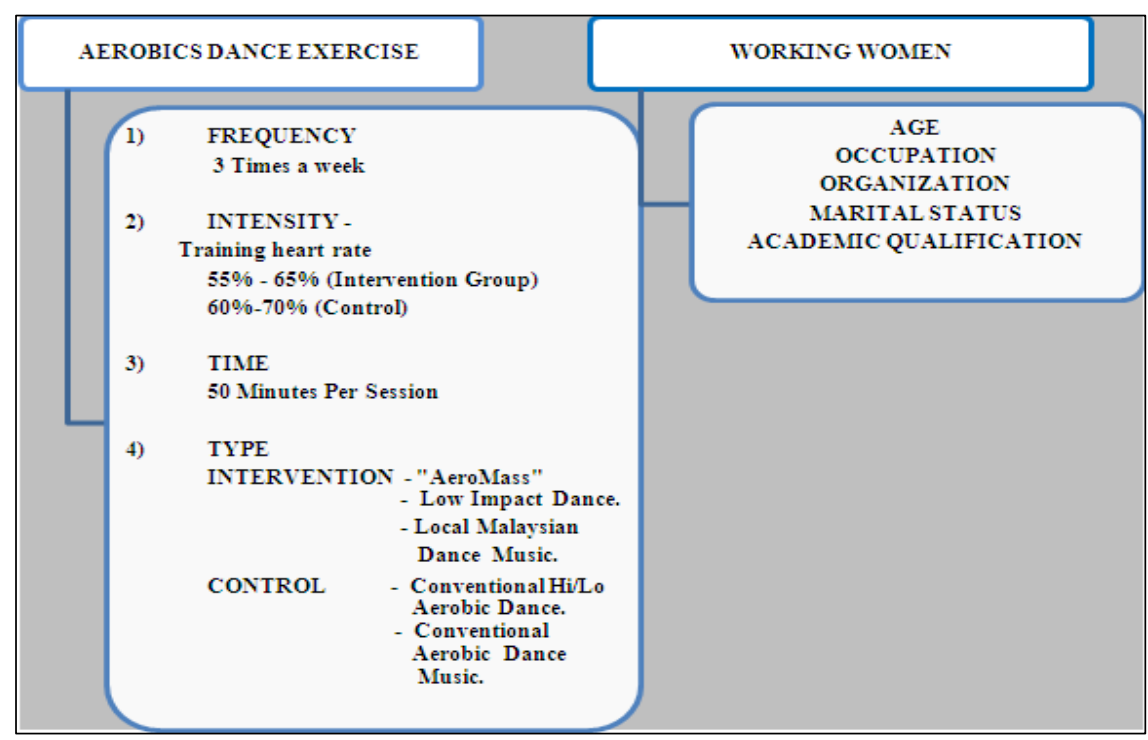

Figure 1. Treatment Assignment \& Pre-test, Post-test Design on Independent Variable 
The population used for this study was sedentary and overweight women working in Malaysia. This study used a convenience sample of 40 employed sedentary overweight women. The subjects were selected on the basis of a degree of homogeneity of their age ranges from 40 until 55 years of age and have not been engaged in any exercise program for the period of more than one year. Subjects were also selected based on their Total Stress Score above mean and their below mean on their cardiovascular components score. From this population, randomize samples of 20 sedentary overweight subjects in a control group and 20 sedentary overweight subjects in an intervention group were selected. Figure 2 shows the homogeneity between treatment and control groups.
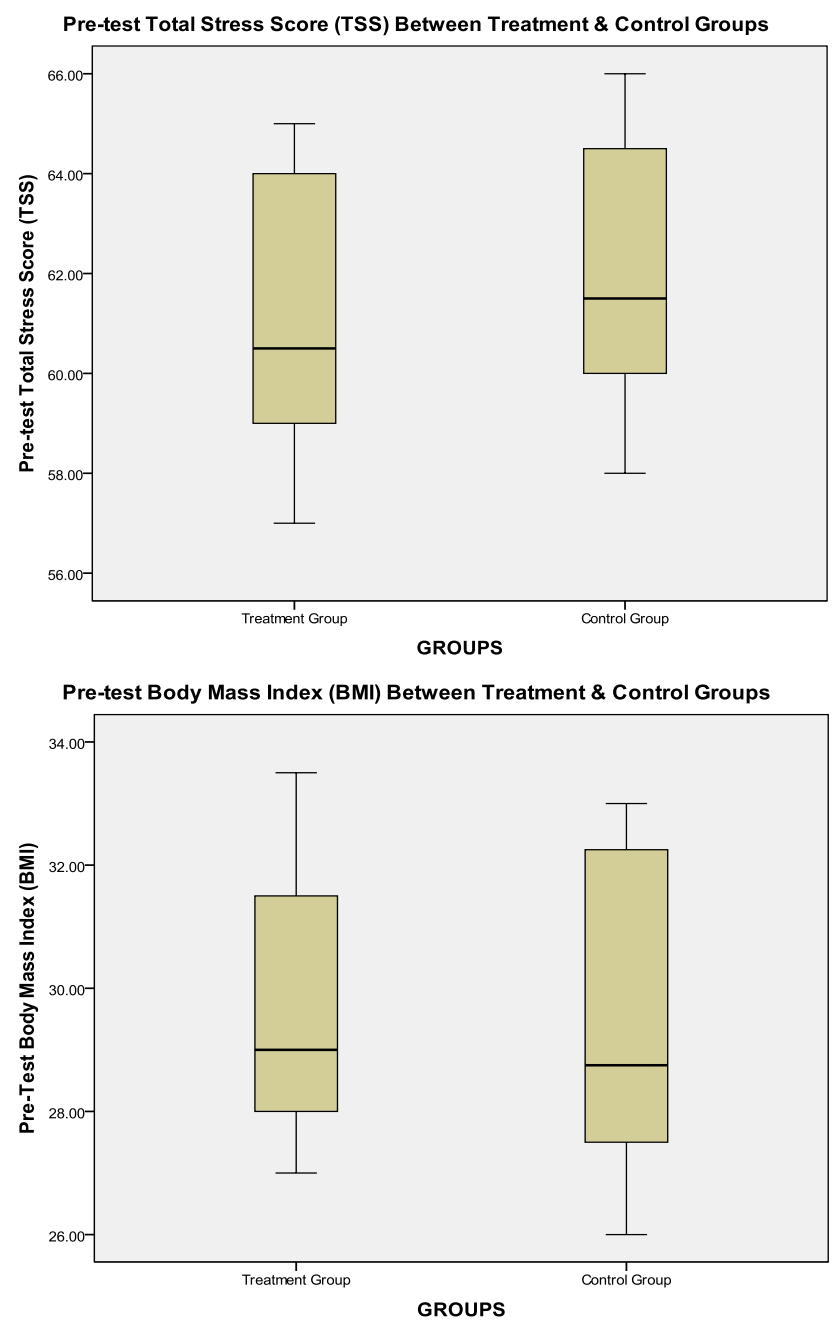

Figure 2. Degree of Homogeneity between treatment and control groups on stress score and body mass index.

\section{Results}

\subsection{Descriptive Data Analysis}

The first set of analyses examined the impact of the descriptive data through exploratory Data Analysis. The purposes of examining the data in details detected errors in coding during the data entry to screen out any unusual values, to identify outliers, to assess the normality of distribution and homogeneity of variance of the population from which samples were drawn. Forty subjects $(n=40)$ of working women between 40 to 55 years of age and was not engaged in any exercise program for the period of more than 6 months before the experiment done were identified. From this population of 74 participants who turn up for the take-off of the pre-test, only 40 participants were chose for this study. The subjects were assigning randomly into two groups, that are control $(n=20)$ and the treatment group $(n=20)$. Subjects chosen for this study obtain Total Stress Score (TSS) above means and those who are overweight and above as according to BMI measurement. The distribution is shown in Table 1 where $(10 ; 25 \%)$ subjects were not married, $(23 ; 57.5 \%)$ were married and $(5 ; 5 \%)$ divorced. Age group was categorized according to 3 ranges where results indicate that age range $40-45(13 ; 32.5 \%), 40-45(7 ; 17.5 \%)$ and majority subjects were in the age range of $51-55(20 ; 50 \%)$. From the total number of subjects involved in this research, $(12 ; 30 \%)$ were Academician, $(14 ; 35 \%)$ were Managerial/Administrator and $(14 ; 35 \%)$ were Support staff which came from private and government organization. Subjects with $\mathrm{PhD} /$ Master were $(11 ; 27.5 \%)$, Degree were $(8 ; 20 \%)$, Diploma were $(10 ; 25.0 \%)$ and SPM/MCE were $(11 ; 27.5 \%)$.

Table 1. Frequency Distribution of Marital Status, Age Category, Job Category \&Academic Level of Subjects.

\begin{tabular}{|c|c|c|}
\hline Variables & Frequency & Percent \\
\hline \multicolumn{2}{|c|}{ Marital Status } & \\
\hline Single & 10 & 25 \\
Married & 23 & 57.5 \\
Divorce & 5 & 17.5 \\
\hline Age Category & & \\
\hline $40-45$ & 13 & 32.5 \\
$46-50$ & 7 & 17.5 \\
$51-55$ & 20 & 50 \\
\hline Job Category & & \\
\hline Academician & 12 & 30.0 \\
Managerial/Administ & 14 & 35.0 \\
rator & 14 & 35.0 \\
Support & & \\
\hline Academic Level & 11 & 27.5 \\
\hline PhD / Masters & 8 & 20.0 \\
Degree & 10 & 25.0 \\
Diploma & 11 & 27.5 \\
SPM/MCE & & \\
\hline Race & 31 & 77.5 \\
\hline Malay & 6 & 7.5 \\
\hline Chinese & 3 & \\
Indian & & \\
\hline
\end{tabular}

\subsection{Statistic}

Repeated measure MANOVA was performed to investigate groups' differences in Hostility, Anxiety and Depression. Preliminary assumption testing was conducted to check for normality, linearity, univariate and multivariate 
outliers, homogeneity of variance-covariance matrices, and multicollinearity, with no serious violations noted. The results of this study shows all the three variable of stress, shows statistically significant difference on "Aero-mass" the treatment group compare to the convention aerobics dance on the control group. There was a statistically significant differences between*group effect (between treatment and control groups) on the combined dependent variables: $F$ (4, $35)=20.79, p<.01$, eta square $=.790$. When the results for the dependent variables were considered separately, all the variables of stress reach statistically significance, using a Bonferroni adjusted alpha level, Hostility Sub-scale F $(1,38)$
$=7.16, p<.05$, eta square $=.16$, Anxiety sub-scale, $\mathrm{F}(1,38)$ $=84.67, p<.05$, eta square $=.69$, and depression sub-scale $\mathrm{F}(1,38)=.241, p<.05$, eta square $=.70$. An inspection of the mean scores indicated that treatment group reported an improvement for Hostility sub-scale $(\mathrm{M}=47.70, \mathrm{SD}=3.34)$, Anxiety sub-scale $(\mathrm{M}=35.65, \mathrm{SD}=3.64)$ and for depression sub-scale $(\mathrm{M}=35.65, \mathrm{SD}=2.58)$. As compared to the control group reported Hostility sub-scale $(\mathrm{M}=56.2, \mathrm{SD}=$ $1.43)$, Anxiety sub-scale $(\mathrm{M}=46.05, \mathrm{SD}=5.99)$ and for depression sub-scale $(\mathrm{M}=45.15, \mathrm{SD}=5.54)$. Figure $3-$ 5 provide the graph sub-scale namely: hostility, anxiety and depression.

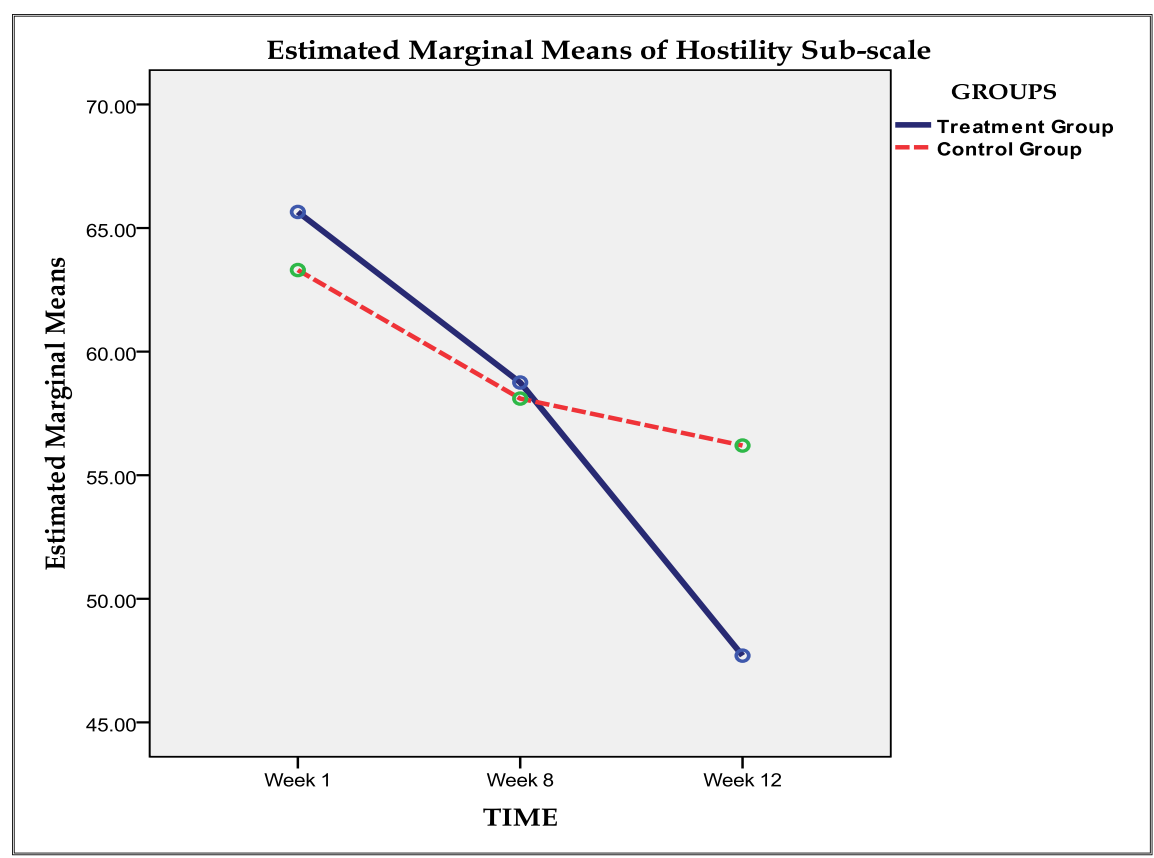

Figure 3. Estimated Marginal Means of Hostility Sub-scale between Treatment and Control Groups

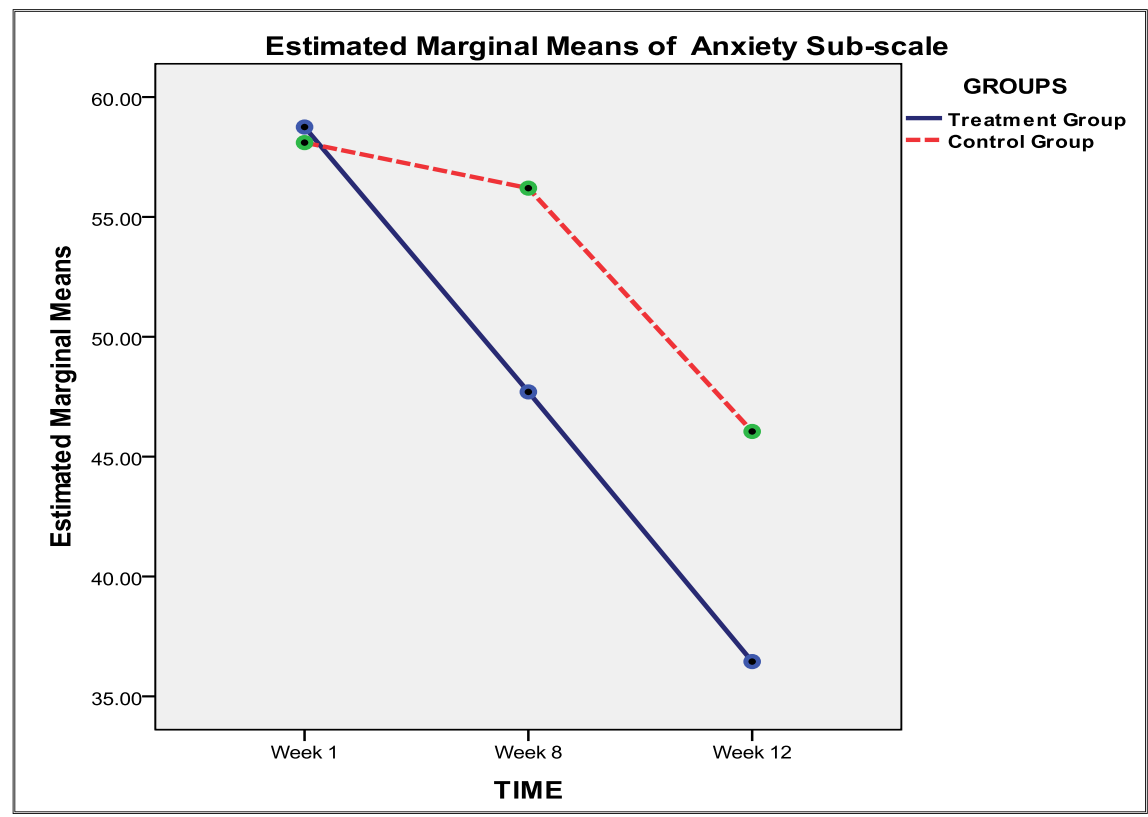

Figure 4. Estimated Marginal Means of Anxiety Sub-scale between Treatment and Control Groups 


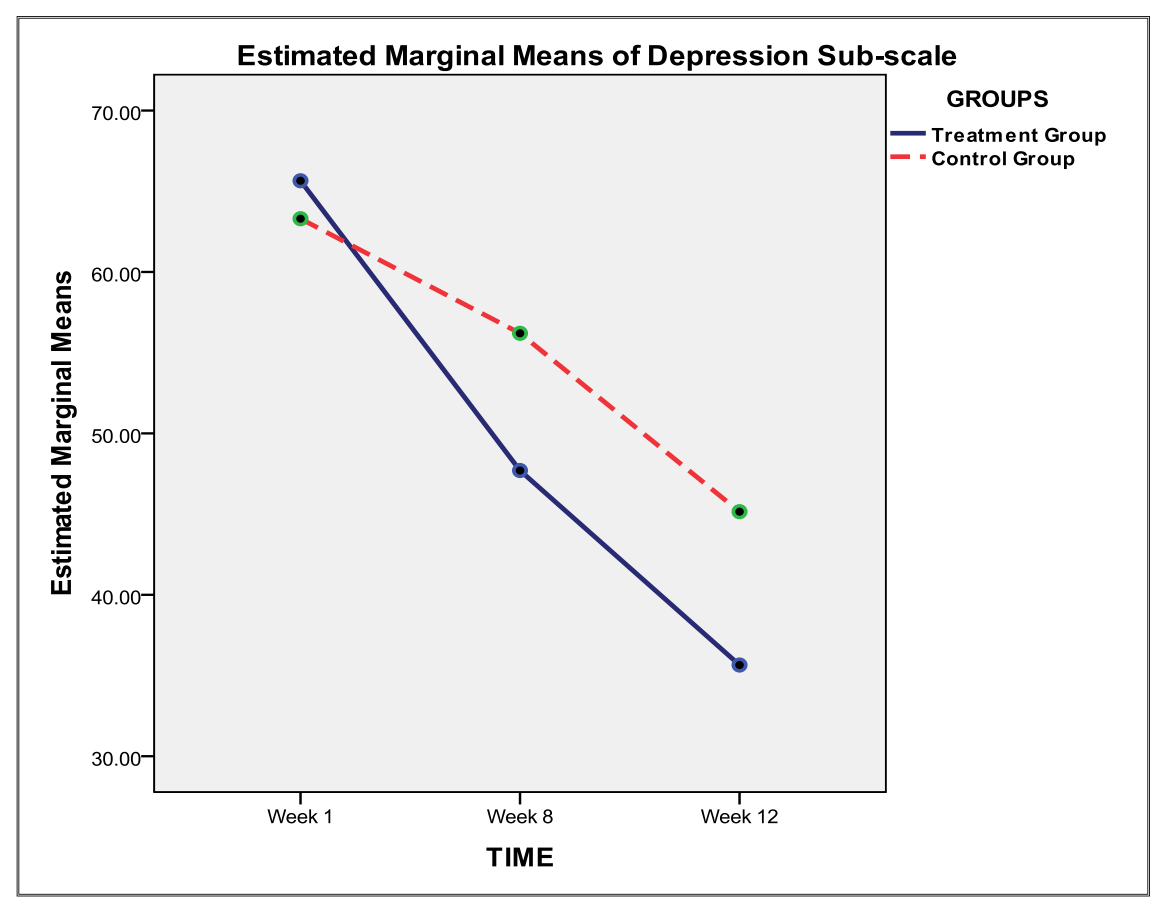

Figure 5. Estimated Marginal Means of Depression Sub-scale between Treatment and Control Groups

Table 2. Results of mixed repeated multivariate analysis of variance (MANOVA) for Hostility, Anxiety and Depression between Treatment \& Control Groups

\begin{tabular}{|c|c|c|c|c|c|c|c|}
\hline \multirow[t]{2}{*}{ EFFECT } & \multirow[t]{2}{*}{ TRIAL } & \multirow[t]{2}{*}{$\mathrm{F}$} & \multirow[t]{2}{*}{ Sig. } & \multirow[t]{2}{*}{ Eta Square } & \multicolumn{3}{|c|}{ Mean Differ } \\
\hline & & & & & $\begin{array}{c}\text { Pretest } \\
\text { to } \\
\text { Postest1 } \\
\end{array}$ & $\begin{array}{l}\text { Postest1 } \\
\text { to Postest2 }\end{array}$ & $\begin{array}{c}\text { Pretest } \\
\text { to } \\
\text { Postest2 }\end{array}$ \\
\hline \multicolumn{8}{|l|}{ Within-Subject } \\
\hline Time*Subject & & 20.64 & $.00 *$ & .98 & & & \\
\hline \multirow[t]{4}{*}{$\begin{array}{c}\text { Between-Subject } \\
\text { Effect }\end{array}$} & & 23.79 & $.00 *$ & .79 & & & \\
\hline & $\begin{array}{l}\text { Sub-scale } \\
\text { Hostility }\end{array}$ & 7.16 & $.01 *$ & .159 & 6.05 & 6.47 & 12.5 \\
\hline & $\begin{array}{l}\text { Sub-scale } \\
\text { Anxiety }\end{array}$ & 84.67 & $.00 *$ & .690 & 6.47 & 10.7 & 17.2 \\
\hline & $\begin{array}{l}\text { Sub-scale } \\
\text { Depression }\end{array}$ & .241 & $.00 *$ & .695 & 12.5 & 11.5 & 24.0 \\
\hline
\end{tabular}

Notes: * The mean difference is significant at the .05 level.

Further to that pair-wise comparison for hostility, anxiety and depression sub-scale, results reported a significant difference $(p<.05)$ across the three time trials. The first pair-wise comparison of pretest - post-test one indicate an improvement with the mean different of Hostility sub-scale $(\mathrm{M}=6.05)$, Anxiety sub-scale $(\mathrm{M}=6.47)$ and depression sub-scle $(M=12$.). It improved constantly at the second paired post-test one - post-test two with the mean difference of Hostility sub-scale $(M=6.47)$, Anxiety sub-scale $(M=$ $10.7)$ and depression sub-scale $(\mathrm{M}=11.5)$. With overall improvement from pretest to post-test two total mean difference of Hostility sub-scale $(\mathrm{M}=12.5)$, Anxiety sub-scale $(M=11.5)$ and depression sub-scle $(M=24)$. Using guidelines proposed by Cohen (1988) $(.01=$ small effect, . .06=moderate effect, . .14=large effect) this result suggest a large effect size. Result shows that $16 \%$ Hostility.
$69 \%$ Anxiety and $69 \%$ Depression of the variability was associated with the treatment after the variability caused by individual differences was removed. To conclude, this study posited a statistically significant difference between the treatment of "Aero mass" and control groups of conventional aerobics dance on stress the dependent variables. The results obtained from the descriptive analysis is shown in Table 2 provides the results on the repeated multivariate analysis of variance (MANOVA).

\section{Conclusions}

The present study intervention program is a therapeutic use of movements that improvise the energy aerobically by using low intensity movements in the dance therapy 
activities manipulating local dance music to improve the mental and physical well-being of a person. It was developed with the embodiment of three movement forms including martial arts, breathing arts and dance forms. It focuses on the connection between the mind (mental skill), internalizing values (affective skill), and body (motor skill) to promote health and healing [18]. The dance exercise is an expressive therapy and it is based on the belief that the mind and body work together and through dance movement aerobics activities, subjects can identify and express their innermost emotions, bringing those feelings to the surface [16]. There are few scientific studies which have been done to evaluate the effects of dance therapy on health, prevention, and recovery from illness [8][16]. Clinical reports suggest that dance is a therapy and may be effective in improving self-esteem and reducing stress [26]. In addition, low intensity dance exercise was reported useful for physical, emotional and mental aspects of the quality of life and it is safe from injuries [26]. Furthermore, the local dance exercise music that was used in the intervention group could be one reason significant results were achieved on psychological well-being variables among the treatment group compared to the control group. Participants in the intervention group reported good attendance and had fun with the intervention routine and the background music improvised during the experiment through the interviews among the participants done by the researcher at the end of the 12-week period.

The findings from this study are able to make several contributions to the current literature. First, psychological well-being does improve with even a low intensity; low intensity dance incorporated with martial arts, movement and dance form contributes more significantly and positively. The American College of Sports Medicine [3] recommends that overweight and obese individuals progressively increase to a minimum of 150 minutes of moderate intensity physical activity per week, but for long-term weight loss, overweight and obese adults should eventually progress to 200 to 300 minutes per week of moderate-intensity physical activity. These are general guidelines; however, the present studies provides additional evidence with respect to that even three times a week of low intensity aerobics dancing at 150 minutes per week of low to moderate intensity does improved the as early as eight week and even more at week 12 if done regularly and consistently on these sedentary overweight women.

In summary, this research will serve as a base for future studies and developments. Study should focus not only on the benefits of psychological aspects but also on the methods used to facilitate dissemination of present and future knowledge in Malaysia. Although some inconsistencies still exist and much research remains to be done, the pursuit of exercise therapy to treat, hostility, anxiety and depression among working women is well underway. All of these research efforts work towards improving the future of preventative medicine and better the well being and lifestyle of employed women suffering from depression to perform and increase productivity in their careers. In short, low intensity exercise routine is indeed simple and cost-effective. It is a fun and safe way to exercise for people from all walks of life. Ultimately, low-impact exercise routine improves the population's physiological and psychological well-being as it promotes one's quality of life.

\section{REFERENCES}

[1] American Dance Therapy Association, (2009)

[2] American Alliance for Health, Physical Education, Recreation \& Dance. (1980). Lifetime Health - Related Physical Fitness Test Manual.

[3] American College of Sports Medicine. (1998). Position stand: The recommended quantity and quality of exercise for developing and maintaining cardiorespiratory and muscular fitness, and flexibility in healthy adults. Medicine and Science in Sports and Exercise, 30 (6), 975-991.

[4] American College of Sports Medicine. (2005). Guidelines for exercise testing and prescription (4th ed.). Philadelphia, PA: Lea \& Febiger.

[5] Bordens, K.S., \& Abbott, B.B. (1996). Research design and methods: A process approaches (3rd ed.). MV, California: Mayfield Publishing Company.

[6] Bradt J, Dileo C. Music for stress and anxiety reduction in coronary heart disease patients. Cochrane Database Syst Rev. 2009 Apr $15 ;(2): C D 006577$.

[7] Cohen, G., Shamus, E., (2009) Depressed, Low Self-Esteem: What Can Exercise Do For You? Allied Health Sciences and Practice, Volume 7 Number 2.

[8] Cooper \& R. Payne (Eds.), Personality and stress: Individual differences in the stress process. Chichester: John Wiley \& Sons

[9] Cooper Institute for Aerobics Research (1992). Aqua aerobics training manual. Dallas, TX: Cooper Institute for Aerobic Research.

[10] Creswell, John W. (2002). Research design: Qualitative, quantitative, and mixed methods approaches. Thousand Oaks, CA: Sage Publications.

[11] Derogatis, L. R. (1980). SCL-90; Administration, scoring and interpretation manual (re.ed). Baltimore, MD: Clinical Psychometrics Unit, Johns Hopkins University School of Medicine.

[12] Derogatis, L.R. (1987). The Derogatis Stress Profile (DSP): Quantification of psychological stress. Advances in Psychosomatic medicine, 17, 30-54.

[13] Derogatis. L.R., \& Coons, H.L. (1993). Self-report measures of stress. In L. Goldberger \& S. Breznitz (Eds.), Handbook of stress: Theoretical and clinical aspects (2nd ed.). New York: The Free Press.

[14] Hermon, D. A. \& Hazler, R. J. (1999). Adherence to a wellness model and perceptions of psychological well-being. Journal of Counseling \& Development, 77, 339-346.

[15] Karageorghis, C. I., \& Terry, P. C. (1997). The 
psychophysical effects of music in sport and exercise: A review. Journal of Sport Behavior, 20, 54-68.

[16] Kern, D.L. (1995). The effect of an internally directed teaching approach in aerobic dance on selected health variables. Dissertation Abstracts International: Section A: Humanities and Social Sciences, 55 (11-A), 3421.

[17] Kern, D. \& and Baker, J.B. (2009) A comparison of a mind/body approach versus a conventional approach to aerobic dance. Women's Health Issues, Vol 7, No.1 Jan/Feb 1997.

[18] Krathwohl, D. R., Bloom, B. S., \& Masia, B. B. (1973). Taxinimy of Education Objectives, the Classification of Educational Goal. Hanbook II: Affective Domain. New York: David McKay Co., Inc.

[19] Kreutz G., Bongard S., Rohrmann S., Hodapp V., Grebe D.(2004) Effects of choir singing or listening on secretory immunoglobulin A, cortisol and emotional state. Journal of Behavioural Medicine 27:623-634

[20] Layman, E. M. (1960). Contributions of exercise and sports to mental health and social adjustment. In W. R. Johnson (Ed.), Science and medicine of exercise and sports (pp. 560-599). New York: Harper \& Brothers.

[21] Mastura, Rozita \& Mohd Sofian. (2008). Qualitative study: Influence of aerobic exercise on state and trait anxiety among working women, International Journal for Education Studies, $1,67-76$

[22] Ministry of Health Malaysia (2002, June 22). Speech by YB. Dato' Chua Jui Meng, Minister of Health Malaysia, at the opening of the 9th Malaysian Conference on Psychological Medicine, Sunway Lagoon Resort Hotel, Malaysia.

[23] Ministry of Health Malaysia (2011). Healthy lifestyle campaign 2000. Retrieve July 20, 2002, from http://prosakti.nstp.com.my/HealthyLifestylele.html

[24] Ministry of Human Resources Malaysia (2001, August 7). Keynote address by YB. Dr. Haji Abd.iff bin Ahmad, Deputy Minister of Human Resources, at the National Conference on Occupational Safety and Health, MIECC, Seri Kembangan. Retrieved July 20, 2003, from: http://www.mohr. gov.my/makluman/spdm23.htm

[25] Pates, J., Karageorghis, C. I., Fryer, R, \& Maynard, I. (2003).
Effects of asynchronous music on flow states and shooting performance among netball players. Psychology of Sport and Exercise, 4, 413-427.

[26] Sandel SL, Judge JO, Landry N, Faria L, Ouellette R, Majczak M. Dance (2005) and movement program improves quality-of-life measures in breast cancer survivors. Cancer Nurs.; 28:301-309.

[27] Schmitt, B., \& Frolich, L. (2007). Creative therapy options for patients with dementia - a systematic review. Fortschr Neurology Psychiatry, 75, 699-707.

[28] Shadish, W.R., Thomas D. Cook, and Donald T. Campbell, D.T. (2002). Experimental and quasi-experimental designs for generalized causal inference. Boston: Houghton-Mifflin. An update of a classic by a third author.

[29] Smuts, J. (1926). Holism and evolution. Westport, CT: Greenwood Press.

[30] Spintge, R.; Droh R. "The International Society of Music in Medicine (ISMM) and the Definition of MusicMedicine and Music Therapy". Spingte, Droh, Ed. MusicMedicine. MMB Music, Inc. St. Louis, 1992. 3-5.

[31] Stuckey, H. L., \& Nobel, J. (2010). The connection between art, healing, and public health: A review of current literature. American Journal of Public Health, 100(2), 254-263.

[32] Szmedra, L., \& Bacharach, D. W. (1998). Effect of music on perceived exertion, plasma lactate, norepinephrine and cardiovascular hemodynamics during treadmill running. International Journal of Sports Medicine, 19, 32-37.

[33] Terry, P. C., Dinsdale, S. L., Karageorghis, C. I., \& Lane, A. M. (2006). Use and perceived effectiveness of pre-competition mood regulation strategies among athletes. In M. Katsikitis (Ed.), Psychology bridging the Tasman: Science, culture and practice - Proceedings of the 2006 Joint Conference of the Australian Psychological Society and the New Zealand Psychological Society (pp. 420-424). Melbourne, VIC: Australian Psychological Society.

[34] Weinberg, R.S. and Gould, D. (2007). Foundations of Sport and Exercise Psychology (4th Ed.), Champaign, IL: Human Kinetics.

[35] Wilkinson, N.; Srikumar, S.; Shaw, K.; \& Orrell, M. (1998). Drama and Movement Therapy in Dementia: a pilot study. The Arts in Psychotherapy, 25(3), 195-201. 